\title{
Preface
}

\section{Redefining Communication: Social Media and the Age of Innovation, an Introduction}

Difference is what defines us, makes us go further, helps us react and create. Considering redefining communication might help us understand what connects us and makes us distinct. The dialogue between the past and present allows us to rethink our habits and re-consider our practices.

Hein (2019:1) ${ }^{1}$ states: 'Life begins with an inhale and ends with an exhale. In-between we all breathe and live different lives. And yet, each breath keeps us together, connected, sharing the same air'. As human beings, we have so many things in common and yet we are so different. With the rise of Social Media in our lives, can we consider that we use innovative ways to communicate? Can such practices encourage us to appreciate and respect values and principles that define us as human beings?

Our special issue discusses how to redefine the way we communicate and how can technical innovation (semantic technologies, Digital Forensics, social media) 'protect us' and bring us together. In this special issue, we present five articles that discuss how we can better connect, collaborate, and innovate to avoid misinformation and cultural loss. Two articles refer to the field of New Media/Innovation and three refer to Cultural Communication, Traditions and National Heritage.

Multimodal news authentication as a service: The «True News» Extension, by Anastasia Katsaounidou, Nikolaos Vryzas, Rigas Kotsakis, and Charalampos Dimoulas, provide us with solutions in identifying fake content, according to fact-checking tools, and utilize them in automated/semi-automated mechanisms, as the key to defend the truth and avoid misinformation. The main novelty of the proposed tool is for users to help determine whether they can trust an article or not, using a simplified and educational tool. The proposed methodology attempts to introduce a valuable free tool in the field of Digital Forensics.

The second paper, Towards a semantic-oriented model of participatory journalism management: Perceptions of user-generated content, by Theodora Saridou, Kosmas Panagiotidis, Nikolaos Tsipas, and \& Andreas Veglis, defines the requirements and describes the characteristics of a new managing participatory journalism model, based on semantic technologies. This new model is proposed by the authors to support organized collection and moderation of content in an effective way and in a short amount of time. The findings lead to a collaborative, semantic-oriented way of submitting and receiving user-generated content. We have a long way to go to understand preferences and new practices in innovation, nevertheless it is encouraging that the young generation is keen on developing knowledge on the topic. More particularly, it is encouraging that a recent research (Podara et al., 2019), confirmed that millennial generation need to rely to its own research about the credibility of a news' topic that appears on the internet.

\footnotetext{
${ }^{1}$ Jeppe Hein is a Berlin-based Danish Artist that created 'Breathe with Me'. This artwork was initiated to engage audiences worldwide with their breath and the UN Sustainable Development Goals. See at https://www.breathewithme.world/breathe-with-me/ , and https://breathewithme.world/breathing-watercolours/ , accessed 25/11/2019
} 
Azian Muhamad Adzmi, from the UK, author of the third paper of this special issue with Social Media and 'Silaturrahim'. The study investigates how emigrated Malaysians maintain their tradition of 'silaturrahim' (togetherness- bond) with the help of new media. Her findings indicate that the increasing use of social media, as a platform of maintaining or improving 'silaturrahim', could establish a positive communication culture among the diaspora community.

Culture is produced, shaped and transmitted through intergroup relations and communication. Margarita Kefalaki, Eirini Daskalaki and Fotini Diamantidaki, present the next paper of this special issue, entitled Cultural Communication and Cultural Transmission: The Case of Popular Tradition in Corsica. This paper suggests a change in taught communication modules in order to achieve cultural transmission, evolution and ways to avoid a possible cultural loss. Exchange and communicate, especially when popular tradition is concerned, could lead to openness, understanding and collaboration of different people and countries around the world. And how much we need it, today more than ever, to learn to co-exist in diverse societies where there are harmonic relationships and mutual respect, despite cultural differences, in today's 'innovative' societies, is food for thought.

Last but not least, the study of Athina Papageorgiou, and Aristidis Papagrigoriou, Athens as a Major Congress Destination and the Role of Professional Congress Organizers (PCOs), examines the type of communication needed for Athens to become a city of major congress events attractor. Results from the study show that joint efforts, from the state and the private sector and certain congress tourism stakeholders, are needed. These efforts can help the capital, largest city of Greece and historical capital of Europe, to be promoted and be established as a major congress tourism destination.

We very much hope that you will enjoy navigating through the articles and considering the dynamics between innovation and communication in this new era of social media and how innovative digital tools can help us move forward and re-create our present and define our future.

\section{Dr Margarita Kefalaki and Dr Fotini Diamantidaki}

\section{References}

Art 2030 (2019) https://www.breathewithme.world/art2030/ (accessed 25/11/2019)

Breathe with me (2019) https://www.breathewithme.world/breathe-with-me/ (accessed 25/11/2019).

Hein J. (2019) https://www.jeppehein.net/ (accessed 25/11/2019)

Podara A., Matsiola M., Maniou T., Kalliris G. (2019). News usage patterns of young adults in the era of Interactive Journalism. In Brahmi M. \& Kefalaki M., (Eds) (2019) Special Issue: International Perspectives in Politics and Journalism, Strategy and Development Review, Volume 9, Special Issue, September 2019, Algeria. P-ISSN: 2170-0982, E-ISSN: 2600-6839 (http://rsd.univ-mosta.dz/index.php/review/volume-09/review-special-issue-athens-greece) 